TABLE IV-Effect of gold treatment on mean NAG excretion and maximum concentrating power

\begin{tabular}{|c|c|c|c|c|}
\hline & \multicolumn{2}{|c|}{$\begin{array}{c}\text { Low-salicylate group } \\
(\mathbf{n}=10)\end{array}$} & \multicolumn{2}{|c|}{$\begin{array}{l}\text { High-salicylate group } \\
\qquad(\mathrm{n}=10)\end{array}$} \\
\hline & Gold $(n=3)$ & $\begin{array}{c}\text { No } \\
\text { gold }(n=7)\end{array}$ & Gold $(n=7)$ & $\begin{array}{l}\text { No } \\
\text { gold }(n=3)\end{array}$ \\
\hline NAG (nmol h-1 mg & 67 & 101 & 241 & 263 \\
\hline $\begin{array}{l}\text { Concentrating power } \\
(\mathrm{mmol} / \mathrm{l})\end{array}$ & 795 & 784 & 687 & 713 \\
\hline
\end{tabular}

caused impairment of medullary function (table IV) and the same was found for corticosteroids. A study of NAG excretion in patients with non-inflammatory joint disease has shown that non-steroidal anti-inflammatory drugs do not increase enzyme excretion, ${ }^{18}$ and possibly also there is some form of continuing renal damage in patients with RA irrespective of their treatment. ${ }^{19}$ It seems that salicylate may cause a mild disturbance of function in addition to this. The functional changes would be consistent in severity with the evidence of chronic interstitial nephritis seen in biopsy and necropsy material. Nevertheless, in view of the lack of evidence that salicylates cause any severe renal damage there is no need to deny patients their undoubted therapeutic benefits because of the fear of causing renal damage.

\section{References}

1 Duthie, J J R, et al, Annals of the Rheumatic Diseases, 1964, 23, 193.

2 Lawson, A A H, and Maclean, N, Annals of the Rheumatic Diseases, 1966, 25,441 .

${ }^{3}$ Garnett, E S, Parsons, V, and Veall, N, Lancet, 1967, 1, 818.

4 Chantler, C, Clinical Science, 1969, 37, 169.

${ }^{5}$ Wrong, O, and Davies, H E F, Quarterly fournal of Medicine, 1959, 110, 259.

${ }^{6}$ Tucker, S M, et al, Clinica Chimica Acta, 1975, 62, 333.

7 Scott, J T, Denman, A M, and Dorling, J, Lancet, 1963, 1, 344.

8 Prescott, L F, Lancet, 1965, 2, 91.

${ }^{9}$ Leatherwood, P D, and Plummer, D T, Biochemical fournal, 1969, 114, 197.

${ }^{10}$ Levy, G, and Leonards, J R, in The Salicylates, ed M J H Smith, and P K Smith, p 5. New York, Wiley, 1966.

11 Steele, T W, Gyory, A Z, and Edwards, K D G, British Medical fournal, $1969,2,213$.

12 Beeley, L, and Kendall, M J, British Medical fournal, 1971, 1, 707.

13 Robert, M, et al, British Medical fournal, 1972, 2, 467.

14 Nanra, R S, Chirawong, P, and Kincaid-Smith, P, Renal Infection and Renal Scarring, p 347. Melbourne, Mercedes, 1971.

15 New Zealand Rheumatism Association, British Medical fournal, 1974, 1 , 593.

${ }^{16}$ Burry, A F, Nephron, 1968, 5, 185.

17 Ellis, B G, Price, R G, and Topham, J C, Chemical Biological Interactions, 1973, 7, 101.

18 Dieppe, P A, et al, Rheumatology and Rehabilitation, 1975, 14, 226

19 Dieppe, P A, Tucker, S M, and Burry, H C, Scandinavian fournal of Rheumatology, 1975, 4, suppl 8, abstract No 28-03.

\title{
Failure of BCG immunostimulation to affect the clinical course of Burkitt's lymphoma
}

\author{
I T MAGRATH, J L ZIEGLER
}

British Medical fournal, 1976, 1, 615-618

\begin{abstract}
Summary
A controlled randomised trial was carried out to evaluate the efficacy of BCG immunotherapy in preventing relapse in patients with Burkitt's lymphoma in whom remission had been induced with cyclophosphamide. Twenty-one patients were treated with BCG, and 19 were controls. Eleven patients in each group relapsed during a follow-up period long enough to make it unlikely that further relapses would occur. There were no significant differences in the length of remission or the site of relapse that could be attributed to treatment. Eleven patients died: of these none of the six patients in the BCG group but all of the five in the control group had stage D lymphomas.

BCG treatment increased the rate of recovery from tumour-induced immunosuppression, but within the BCG group immunocompetence improved most rapidly in the patients who relapsed-a finding that appears to contradict the tenet rationalising the use of immunological adjuvants as treatment.
\end{abstract}

Lymphoma Treatment Centre, Makerere University Medical School, Uganda Cancer Institute, Kampala, Uganda

I T MAGRATH, MB, MRCP, director, Lymphoma Treatment Centre (present address: Paediatric Oncology Branch, National Cancer Institute, Bethesda, Maryland, USA)

J L ZIEGLER, MD, director, Uganda Cancer Institute (present address: Paediatric Oncology Branch, National Cancer Institute, Bethesda, Maryland, USA)
These results provide no evidence that BCG has a therapeutically beneficial effect on a tumour which, theoretically, should respond to non-specific immunotherapy. Rather, some of the results indicate that BCG treatment may actually have been deleterious.

\section{Introduction}

Burkitt's lymphoma responds dramatically to chemotherapy, and the high frequency of sustained remission indicates that a cure is possible. ${ }^{1}$ Nevertheless, about two-thirds of patients relapse during the first year, and about half of these eventually die with a tumour resistant to chemotherapy. ${ }^{12}$ Attempts to prevent relapse by intensifying chemotherapy have so far proved unsuccessful. ${ }^{134}$ Evidence for the existance of tumourdirected immunological reactions and their correlation with clinical status ${ }^{6-9}$ prompted us to evaluate immunotherapy in a controlled randomised trial. We report here the effect of nonspecific immunostimulation with BCG on the clinical course of patients in whom remission had been induced by a standard moderate amount of chemotherapy.

\section{Patients and methods}

CLINICAL TRIAL

All patients with untreated Burkitt's lymphoma admitted to the Lymphoma Treatment Centre, Kampala, from February 1971 to July 1973 were included in the trial. The diagnosis of Burkitt's lymphoma was established according to the criteria of the World Health Organisation ${ }^{10}$ by histological examination and cytology of imprints or fine-needle tumour aspirates. ${ }^{11}$ Tumour sites were determined by clinical and radiological examination ${ }^{14}$ and examination of cerebrospinal fluid (CSF) for tumour cells. Tumours were 
clinically staged as follows: stage I-localised facial tumour; stage IItwo or more facial tumours; stage III-intrathoracic, intra-abdominal, or osseous tumour (excluding jaws) and paraplegia; stage IVmeningeal or generalised bone marrow metastases.

Intravenous cyclophosphamide $40 \mathrm{mg} / \mathrm{kg}$ was given as soon as initial studies were complete and repeated two weeks later. Occasionally, when we thought that complete remission had not been achieved, a third dose was given after a further two weeks. Patients with meningeal deposits were given two four-day courses of intrathecal treatment ${ }^{12}$ and some of the remaining patients received, by random allocation, 1-(2 chloroethyl)-3-cyclohexyl-1-nitrosourea (CCNU) $70 \mathrm{mg} / \mathrm{m}^{2} .^{13}$ Patients in complete remission two weeks after the last dose of cyclophosphamide were randomised by stage to receive BCG or no further treatment.

BCG was administered by scarification by the method of Mathé. ${ }^{14}$ Pasteur Institute lyophilised BCG was used; $0.5 \mathrm{ml}$ of a freshly reconstituted suspension containing $150 \mathrm{mg}$ of BCG dry weight and about $3 \times 10^{8}$ viable organisms (according to the manufacturer) was given at each application. Scarification was performed on each limb in turn every four days for seven doses and then weekly for six doses, giving a total of 10 weeks' immunotherapy.

\section{IMMUNOLOGICAL STUDIES}

Serial sera were stored at $-20^{\circ} \mathrm{C}$ before testing for Epstein-Barr virus associated antibodies, anti-virus capsid antigen (anti-VCA), ${ }^{15}$ anti-early antigen (anti-EA), ${ }^{16}$ and anti-membrane antigen (antiMA). ${ }^{17}$

All patients were also tested for cutaneous reactivity to intermediate strength tuberculin (purified protein derivative; PPD), mumps, candidin, streptokinase-streptodornase (SK-SD), ${ }^{18}$ and cell membrane extracts of two long-term cultured Burkitt's lymphoma cell lines, Raji and $\mathrm{P}_{3} \mathrm{HRI}$. When possible cutaneous reactivity to membrane extracts of autochthonous tumour and control leucocytes obtained from peripheral blood was also assessed. ${ }^{8}{ }^{9}$ The sum of the individual diameters of induration to mumps, candidin, and SK-SD, combining 24- and 48-hour readings, was used as a quantitative index of delayed (utaneous hypersensitivity. ${ }^{18}$

\section{Results}

Eighty patients were admitted to the trial but 32 were ineligible for the BCG stage of the trial-six because of previous treatment, six because they died, 10 because they responded only partially to cyclophosphamide, two because of early relapse, seven because they defaulted on appointments, and one because of eventually fatal osteomyelitis complicating paraplegia. Five further patients (three on BCG and two controls) relapsed within two weeks of randomisation, two controls were lost to follow-up, and one control died in remission four weeks after randomisation; none of these patients could be evaluated. The remaining patients ( 21 receiving BCG and 19 controls) were followed up until relapse or death or for at least 33 weeks, a period in which over $90 \%$ of relapses would be expected to occur. The median follow-up period for non-relapsing patients was 91 weeks (33-161 weeks).

There were no significant differences in age, stage of tumour, or treatment between the two groups (table I). Eleven of the 21 BCGtreated patients and 11 of the 19 controls relapsed. The percentage of patients achieving sustained remission was similar in both groups (fig 1). An analysis of relapse sites showed that six of the 11 relapses in the BCG-group affected only the nervous system-that is, the patient developed cranial neuropathy or CSF malignant pleocytosiscompared with one of the 11 relapses in the control group. This difference suggested initially that BCG treatment protected against systemic relapse but failed to avert neurological relapse. ${ }^{19}$ Since the overall frequency of neurological relapse in the BCG group was

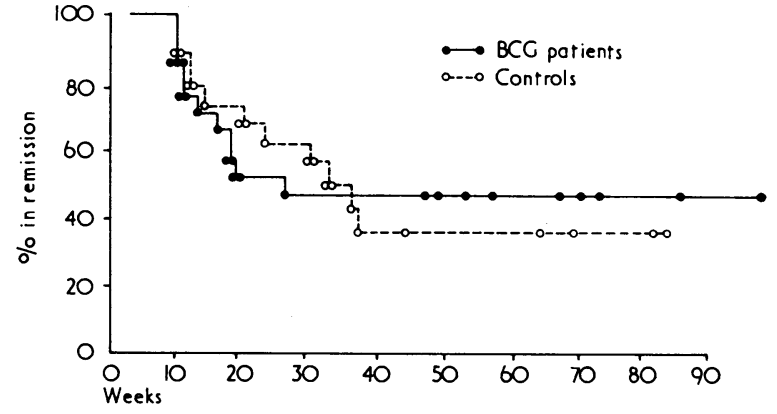

FIG 1-Actuarial curves of length of remission in BCG and control groups.

actually greater than in the control group, however, this explanation was unacceptable.

We then restaged the tumours in our patients as follows: stage $\mathrm{A}-$ single localised extra-abdominal tumours; stage B-multiple extraabdominal tumours; stage $\mathrm{C}$-intra-abdominal tumours with or without single facial tumours; stage $\mathrm{D}$-stage $\mathrm{C}$ tumours with additional extra-abdominal tumours; stage AR-abdominal tumours that have been completely resected. This newer staging system allows a more accurate prediction of relapse rate and survival to be made, ${ }^{20} 21$ and when it was applied to our patients a significant imbalance between the BCG and control groups became apparent (table II). Furthermore, we found that among 169 patients with Burkitt's lymphoma seen at this centre who subsequently relapsed (not including BCG-treated patients) patients with stage B tumours had isolated neurological relapse three times as often $(24 \%)$ as those with stage $D$ tumours $(8 \%)$. In addition, patients with stage $\mathbf{A}$ or $\mathbf{B}$ tumours and either paraplegia or nervous system involvement at presentation had a par-

TABLE II-Number of tumours of each stage (new classification) in both groups

\begin{tabular}{|c|c|c|c|c|c|c|c|c|}
\hline & Stage: & & A & $\mathrm{B}^{*}$ & C & $\mathrm{D}^{*}$ & AR & Total \\
\hline $\begin{array}{l}\text { BCG patients } \\
\text { Controls } \ldots\end{array}$ & 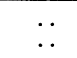 & $\begin{array}{l}\cdots \\
\cdots\end{array}$ & $\begin{array}{l}3 \\
3\end{array}$ & $\begin{array}{r}10(48 \%) \\
2(11 \%)\end{array}$ & $\begin{array}{l}2 \\
3\end{array}$ & $\begin{array}{l}4(19 \%) \\
9(47 \%)\end{array}$ & $\begin{array}{l}2 \\
2\end{array}$ & $\begin{array}{l}21 \\
19\end{array}$ \\
\hline
\end{tabular}

* The inversion in the ratio of stage B:D tumours between the groups was significant ( $P<0.01, \chi^{2}$ test).

ticularly high rate of this form of relapse ( $41 \%$ and $38 \%$ respectively). Thus the greater number of patients in the BCG group categorised as having stage B or stage A or B tumours with paraplegia or nervous system disease (six compared with two in the control group) was sufficient to account for the increased incidence of isolated neurological relapse in patients given immunotherapy. The validity of these findings was confirmed by identifying a group of retrospective controls who were individually matched as closely as possible to the BCG group by treatment (no more than three doses of cyclophosphamide), actual tumour site, age, and sex (in that order). The overall incidence of relapse, the site, and the length of remission were similar in both groups, and there was no difference in isolated neurological relapse between the two groups.

Six patients in the BCG group died: one after apparently uncomplicated surgery for removal of a recurrent abdominal tumour, one from a presumed idiosyncratic reaction to intrathecal methotrexate, one from bronchopneumonia that followed a neurological relapse and a long period of bed rest, two with recurrent tumour, and one from unknown causes while in remission; none of these patients had stage D tumours. Five patients in the control group have died, all with recurrent chemotherapy-resistant tumours; all tumours were stage $D$.

TABLE I-Staging and treatment in both groups of patients

\begin{tabular}{|c|c|c|c|c|c|c|c|c|c|c|c|c|c|}
\hline & & & \multirow{2}{*}{$\begin{array}{c}\text { No of } \\
\text { patients }\end{array}$} & \multirow{2}{*}{$\begin{array}{l}\text { Male: } \\
\text { female } \\
\text { ratio }\end{array}$} & \multirow{2}{*}{$\begin{array}{c}\text { Mean age } \\
\text { (and range) } \\
\text { (years) }\end{array}$} & \multicolumn{4}{|c|}{ Original stage } & \multicolumn{4}{|c|}{ Treatment } \\
\hline & & & & & & I & II & III & IV & CCNU & $\underset{\times 2}{\text { Cyclophosphamide }}$ & $\underset{\times 3}{\text { Cyclophosphamide }}$ & $\begin{array}{l}\text { Intrathecal } \\
\text { treatment }\end{array}$ \\
\hline $\begin{array}{l}\text { BCG patients } \\
\text { Controls }\end{array}$ & $\because$ & $\because$. & $\begin{array}{l}21 \\
19\end{array}$ & $\begin{array}{l}15: 6 \\
14: 5\end{array}$ & $\begin{array}{c}10(4-65)^{*} \\
6(3-14)\end{array}$ & $\frac{1}{2}$ & $\begin{array}{l}4 \\
3\end{array}$ & $\begin{array}{l}14 \\
13\end{array}$ & $\begin{array}{l}2 \\
1\end{array}$ & $\begin{array}{l}8 \\
7\end{array}$ & $\begin{array}{l}19 \\
19\end{array}$ & $\begin{array}{l}2 \\
0\end{array}$ & $\begin{array}{l}1 \\
2\end{array}$ \\
\hline
\end{tabular}

* One patient was over 21 years and three were aged 14-20 years. 
EFFECT OF BCG ON IMMUNE SYSTEM

Cutaneous reactivity-Treatment with BCG significantly improved cutaneous reactivity to recall antigens (excluding PPD) after four weeks $(P<0.001$, Mann-Whitney U test). This did not occur in control patients, in whom cutaneous reactivity increased more gradually (fig 2). The clinical stage did not influence the rate of improvement in cutaneous reactivity. Conversion of tuberculin reactions was observed in 14 out of 14 BCG-treated patients (six patients were positive at randomisation) and in six out of 11 controls (three patients were positive at randomisation). In the BCG group the time course of increased reactivity to recall antigens was similar to that of the increased reactivity to PPD. There were no positive cutaneous reactions either before or during the three months after randomisation in six patients in each group who were tested with autochthonous tumour extract (although some transient borderline positive responses were seen subsequently: three in the BCG group and one in the control group). Eight of the 15 BCG-treated patients tested developed positive reactions to lymphoblastoid cell extracts $\left(\mathbf{P}_{3} \mathrm{HRI} 3\right.$, Raji 5) compared with three of the seven controls-an insignificant difference.

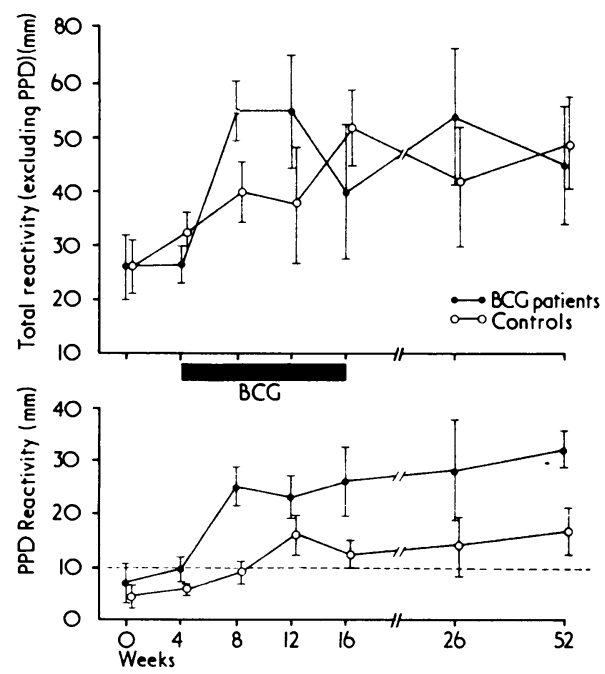

FIG 2-Serial reactivity to $\mathrm{PPD}$ and recall antigens (mumps, candidin, SK-SD) in BCG and control groups. Mean reactivity (combining 24 - and 48 -hour readings) was calculated for patients tested at each interval after randomisation and plotted as mean $\pm \mathrm{SE}$.

Serological studies-There were no differences in the pattern of anti-VCA and anti-EA titres in the two groups before treatment with BCG started. Sixteen patients in the BCG group and 14 in the control group were studied serially for up to two years after randomisation. No consistent alterations in titres were seen in either group, and there were no differences between the groups. In BCG-treated patients there was a highly significant increase in anti-MA levels that did not occur in controls. Further details have been given elsewhere. ${ }^{22}$

\section{CHANGES IN IMMUNOLOGICAL REACTIVITY AND CLINICAL COURSE}

The cutaneous reactivity of patients in the BCG group whose initial remission lasted at least $\mathbf{4 5}$ weeks (after which time relapse in Burkitt's lymphoma is very unlikely ${ }^{2}$ ) was compared with that of relapsing patients in the same group (fig 3). Seven patients who achieved sustained remission and had complete skin test data had overall a significantly smaller increase in cutaneous reactivity to recall antigens after four weeks of BCG treatment than seven completely documented patients who relapsed (fig 3 ). The median increase in the patients in sustained remission was $14 \mathrm{~mm}$ (range $3-29 \mathrm{~mm}$ ), while the median increase over the same period in seven patients who relapsed was $41 \mathrm{~mm}$ (range $17-53 \mathrm{~mm})(P=0.013$, Mann-Whitney $U$ test). Reactivity to PPD before BCG treatment and the increase in PPD reactivity after BCG treatment was similar in patients who achieved sustained remission and in those who relapsed. In the control group five fully documented patients who achieved sustained remission had a median increase of $4 \mathrm{~mm}$ to recall antigens in the four weeks after randomisation, while five patients who relapsed had a median improvement of $8 \mathrm{~mm}$.

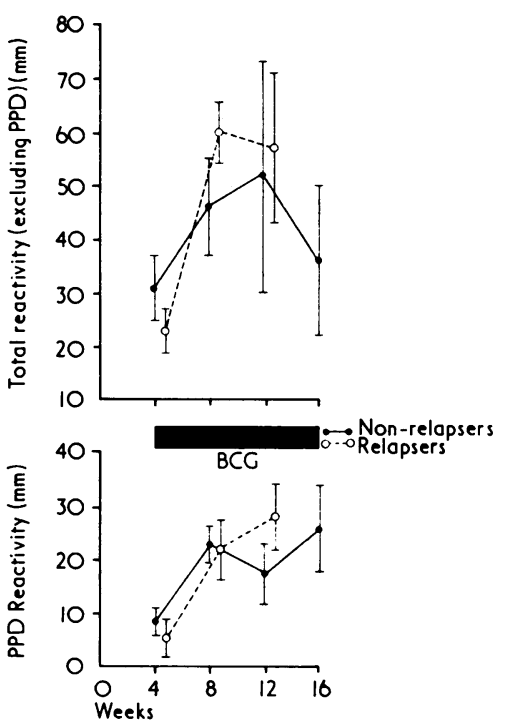

FIG 3-Comparison of cutaneous reactivity to recall antigens and PPD in BCG-treated patients who achieved sustained remission and those who relapsed.

TOXICITY

We saw no systemic toxicity of the type described after intratumoural injection of $\mathrm{BCG}^{23}$ Local scarification reactions subsided in a few weeks, and after a few months there were negligible traces.

\section{Discussion}

The value of immunotherapy as an adjunct to other anticancer treatment has yet to be definitively substantiated in man. Extrapolating from animal studies, the best results are most likely to be obtained when the tumour is strongly immunogenic, ${ }^{24}{ }^{25}$ the host can mount an immune response, ${ }^{23} 26$ and the tumour burden at the start of immunotherapy is minimal. ${ }^{14} 27$ In Burkitt's lymphoma these criteria seem to be fulfilled, or fulfillable. There is evidence, for example, that tumourassociated antigens induce an immune response ${ }^{6-7}$ and that host factors are important to the clinical outcome. ${ }^{28}$ In addition, the high rate of complete remissions after chemotherapy might indicate that the tumour burden, at least in some patients in remission, is small enough for immunotherapy to have a reasonable chance of success, particularly since the patient's immune reactivity, both general and tumour-directed, is recovering at this time from the immunosuppressive effects of the recent tumour. ${ }^{18}$ More prolonged chemotherapy has no effect on relapse rate. ${ }^{34}$ Hence it seemed that Burkitt's lymphoma would provide an excellent model on which to test the hypothesis inherent in the concept of non-specific immunotherapy.

The major immunological effect of BCG in this study was to accelerate the rate of recovery from tumour-induced general immunosuppression, as measured by cutaneous reactivity to recall antigens. The level of immunocompetence reached, however, was no greater than that eventually achieved by the control patients, albeit at a slower rate. There was no evidence that BCG also stimulated a tumour-specific response, although the number of patients tested for cutaneous reactivity to their own tumour was small. Antibody titres to the membrane antigen associated with Epstein-Barr virus (which is present on the surface of Burkitt's lymphoma tumour cells ${ }^{2}{ }^{9}$ ) increased greatly, however, in patients treated with BCG but not in control patients. ${ }^{22}$

Despite the immunological changes that could be ascribed to BCG treatment, there were no significant differences in the relapse rate or site of relapses between the BCG-treated and 
control groups. When only BCG-treated patients are considered, however, the improvement in immunological responsiveness to recall antigens was much greater in those who relapsed than in those who sustained their remission. The same phenomenon was seen, but to a lesser extent, in controls. This unexpected result seems to refute the assumption that adjuvant-induced improvement in overall immune reactivity is beneficial. It might be conjectured that in relapsing patients either tumour immunity was not stimulated at the same time as general immunity-for example, because most of the immunocompetent cells were committed to react against more powerful microbial antigens or because, with respect to tumour-directed reactions, stimulation of suppressor elements of the immune system predominatedor blocking factors were simultaneously increased. A further possibility is that the degree of tumour-directed immune reactivity induced in BCG-treated patients who relapsed actually stimulated tumour growth; this has been described in animals. ${ }^{30} 31$ Our findings indicate that tumour immunity is not necessarily reflected by general immunity-in fact the reverse may sometimes apply-and further emphasise the potential risks of enhancing tumour growth by "therapeutic" immunological manipulation.

We thank the staff of the Lymphoma Treatment Centre, Kampala, for their skilled help. Dr C Olweny helped with the care of some of the patients, and Mr A Kisuule directed follow-up. Sera were tested for anti-VCA and anti-EA by Dr W Henle, Children's Hospital of Philadelphia, and for anti-membrane antigen by Dr P Gunven, Karolinska Institute, Stockholm. Dr R Herberman, National Cancer Institute, Bethesda, provided Burkitt's lymphoma cell lines. Mrs P Magrath provided both clinical and administrative help throughout the trial. This work was supported in part by contract NCI-CM-71343 from the National Cancer Institute, Bethesda, Maryland, and by the Cancer Research Campaign (UK).

\section{References}

${ }^{1}$ Ziegler, J L, Cancer, 1972, 30, 1534.

2 Ziegler, J L, et al, Cancer Research, 1972, 32, 1267.

3 Ziegler, J L, et al, Cancer, 1970, 26, 474.

4 Ziegler, J L, et al, International fournal of Cancer, 1972, 10, 254

5 Burkitt, D P, Cancer, 1967, 20, 756.

${ }^{6} \mathrm{Klein}, \mathrm{G}$, in Burkitt's Lymphoma, ed D P Burkitt and D H Wright. London, Livingstone, 1970.

${ }^{7}$ Stjernsward, J, Clifford, P, and Svedmyr, E, in Burkitt's Lymphoma, ed D P Burkitt and D H Wright. London, Livingstone, 1970.

${ }^{8}$ Bluming, A Z, et al, Clinical and Experimental Immunology, 1971, 9, 713.

- Fass, L, Herberman, R B, and Ziegler, J L, New England fournal of Medicine, 1970, 19, 282

${ }_{10}$ Berard, C, et al, Bulletin of the World Health Organisation, 1969, 80, 601.

${ }^{11}$ Magrath, I T, British fournal of Cancer, 1973, 28, 477.

12 Ziegler, J L, and Bluming, A Z, British Medical fournal, 1971, 3, 108.

${ }^{13}$ Ziegler, J L, et al, Cancer Chemotherapy Reports, in press.

${ }^{14}$ Mathé, E, Pouillart, P, and Lapeyraque, F, British fournal of Cancer, $1969,23,814$

${ }^{15}$ Henle, G, and Henle, W, fournal of Bacteriology, 1966, 91, 1248.

${ }^{16}$ Henle, G, Henle, W, and Klein, G, International fournal of Cancer, $1971,8,272$.

${ }^{17}$ Gunven, P, and Klein, G, fournal of the National Cancer Institute, 1971, $47,559$.

${ }^{18}$ Magrath, I T, International fournal of Cancer, 1974, 13, 839.

19 Ziegler, J L, and Magrath, I T, National Cancer Institute Monograph, $1973,39,199$.

${ }^{20}$ Magrath, I T, et al, British Medical fournal, 1974, 2, 308.

${ }^{21}$ Ziegler, J L, and Magrath, I T, in Pathobiology Annual, ed H L Joachim, p 129. New York, Appleton-Century-Cofts, 1974.

${ }^{22}$ Gunven, P, MD Thesis, 1974, Department of Tumour Biology, Karolinska Institute, Stockholm.

${ }^{23}$ Bast, R C, et al, New England fournal of Medicine, 1974, 290, 1458.

${ }^{24}$ Baldwin, R W, and Pimm, M V, British fournal of Cancer, 1973, 27, 48.

${ }^{25}$ Parr, I, British fournal of Cancer, 1972, 26, 174.

${ }^{26}$ Hanna, M G, et al, fournal of the National Cancer Institute, 1973, 51, 1897.

${ }^{27} \mathrm{Zbar}, \mathrm{B}$, et al, Fournal of the National Cancer Institute, 1972, 49, 119.

${ }^{28} \mathrm{Ngu}, \mathrm{V}$ A, Burkitt, D P, and Osunkoya, B O, in Burkitt's Lymphoma, ed D P Burkitt and D H Wright. London, Livingstone, 1970.

${ }^{29}$ Klein, G, et al, fournal of the National Cancer Institute, 1967, 39, 1027.

${ }^{30}$ Prehn, R, Science, 1972, 176, 170.

31 Jeejeebhoy, H F, International fournal of Carcer, 1974, 13, 665.

\title{
Detection of deep vein thrombosis by Doppler angiography
}

\author{
T K DAY, P J FISH, V V KAKKAR
}

British Medical fournal, 1976, 1, 618-620

\section{Summary}

A new technique, ultrasonic Doppler angiography, was used to examine the deep veins in 50 legs of 40 patients in which deep vein thrombosis was suspected. The results were compared with those of venography. The ultrasound method detected 30 out of 32 venographically confirmed thrombi and showed 17 out of 18 venographically proved normal deep veins. It was equally effective in detecting partial as well as totally occluding thrombi.

\section{Introduction}

The continuous wave ultrasonic Doppler blood-flow detector is a simple instrument for the non-invasive examination of the

King's College Hospital Medical School, London SE5 8RX

T K DAY, MB, MRCP, research fellow

P J FISH, MSC, physicist

V V KAKKAR, FRCS, FRCS ED, consultant surgeon

deep veins of the legs. ${ }^{1-3}$ It is unreliable, however, when used in screening for early, forming asymptomatic thrombi or for confirming the presence of suspected deep vein thrombosis. ${ }^{4}$ The dangerous, partially occluding thrombus likely to produce major pulmonary embolism may be missed because of the difficulty in distinguishing between normal venous flow signals and signals produced by blood passing by a non-occluding thrombus. ${ }^{5}$

Ultrasonic Doppler angiography, ${ }^{6} 7$ a method of imaging the lumen of suspect blood vessels by using ultrasound and the Doppler effect, overcomes the disadvantages of the conventional ultrasonic flow detector while maintaining its advantages. The apparatus consists of a pulsed ultrasonic flow detector and a B-scanner. Such an instrument has been used to detect lesions in arteries. ${ }^{8} 9$ We report here our assessment of the accuracy of ultrasonic angiography as compared with that of phlebography in detecting deep vein thrombosis in cases suspected clinically.

\section{Patients and method}

\section{PATIENTS}

Forty patients with clinical features suggestive of deep vein thrombosis or pulmonary embolism or both referred from medical, 